\title{
A case report: A patient with Crhon's disease clinically characterized by refractory digestive tract blooding and serious hypo-albumin
}

\author{
Cheng $L^{*}$, Xiaoning $S$, Zhoutao $H$ and Xiangyang $H$ \\ Department of Gastroenterology, Hainan General Hospital, Haikou City, 570311, P.R. China
}

\section{Introduction}

Crhon's disease is a kind of autoimmune diseases mainly occurring in digestive tract, which is still difficult to be treated due to its prolonged and refractory characteristic. CD is Clinically characterized by various manes fictions, including abdomen pain, diarrhea, abdominal mass, fistula, etc. Usually it is difficult to make a precise diagnosis, especially when it occurred within small intestine.

\section{Case report}

A 30 years old young man was brought to department of gastroenterology because of refractory black stool for 6 years. The patient had black solid stool, 150g/d, accompanied with dizziness, palpitations and weak. but without abdomen pain, abdominal distension,vomit and mucopurulent bloody stool. The patient was brought to hospital for several times and was treated as digestive tract blooding. But the location and reason of blooding was unclear. He was examined by gastric and colon endoscopy but had no precise diagnosis, even under the small intestine endoscopy and pathological analysis. CT examination only show light degree distension of transverse colon.

PE: T $36.7^{\circ} \mathrm{C} \mathrm{P} 105 / \mathrm{min} \mathrm{R} \mathrm{20/min} \mathrm{BP} 102 / 50 \mathrm{mmHg}{ }^{\circ} \mathrm{mmH}$ Serious anaemia appearance, with no obvious abnormal appearance in heart, lung and abdomen. There was serious edema in his lower trunk.

\section{Helpful Examination}

serum potassium $3.00 \mathrm{mmol} / \mathrm{L}$,Serum albumin $17.7 \mathrm{~g} / \mathrm{L}, \mathrm{C}$ reaction protein $29.75 \mathrm{mg} / \mathrm{L}$, folic acid $25.20 \mathrm{nmol} / \mathrm{L}$, Vitamin B12 $180.0 \mathrm{pmol} / \mathrm{L}$. The antibodies against CMV, EB were negative, as well as T-spot (Figures 1-3).

\section{Treatment}

The patient was treated with thalidomide. He was transferred with red blood cells to revise his serious anemia, with albumin to revise serious hypo-albumin, as well as diuretic therapy, nutrient support in vitro.

After several weeks 'treatment, the patient's symptoms remarkably improved or disappeared. He had no abdomen pain, abdomen distension, black stool, and no edema of lower limbs, with HGB 81g/L, ALB $29.5 \mathrm{~g} / \mathrm{L}$, and CRP $22.9 \mathrm{mg} / \mathrm{L}$.

\section{Discussion}

Digestive tract blooding is not a usual symptom of CD. In our case report, the patient went into hospital for several times due to

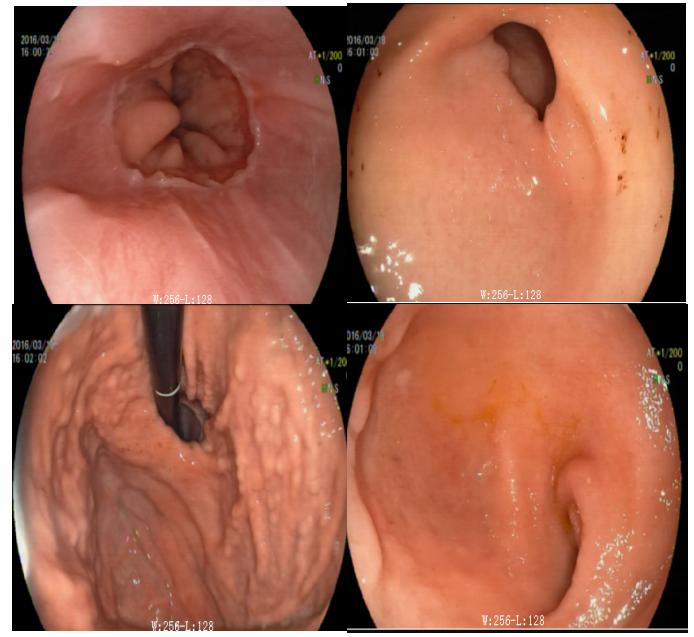

Figure 1. Esophagitis (fungus) Multiple apophysis lesions mul (polyus?), Duodenal bulb inflammation

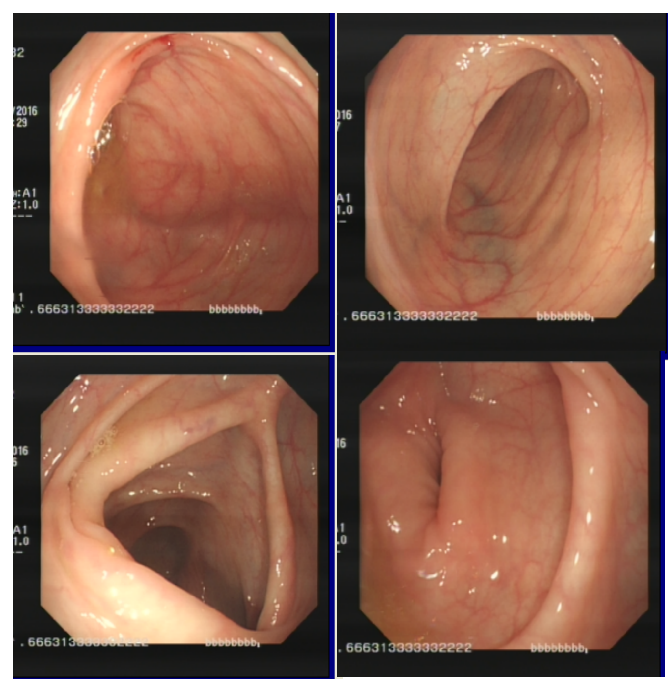

Figure 2. Colon endoscopy: sigmoiditis

${ }^{\star}$ Correspondence to: Cheng Lan, Department of Gastroenterology, Hainan General Hospital, Haikou City, PR China, E-mail: lancheng71@163.com

Received: October 08, 2018; Accepted: October 23, 2018; Published: October 25,2018 


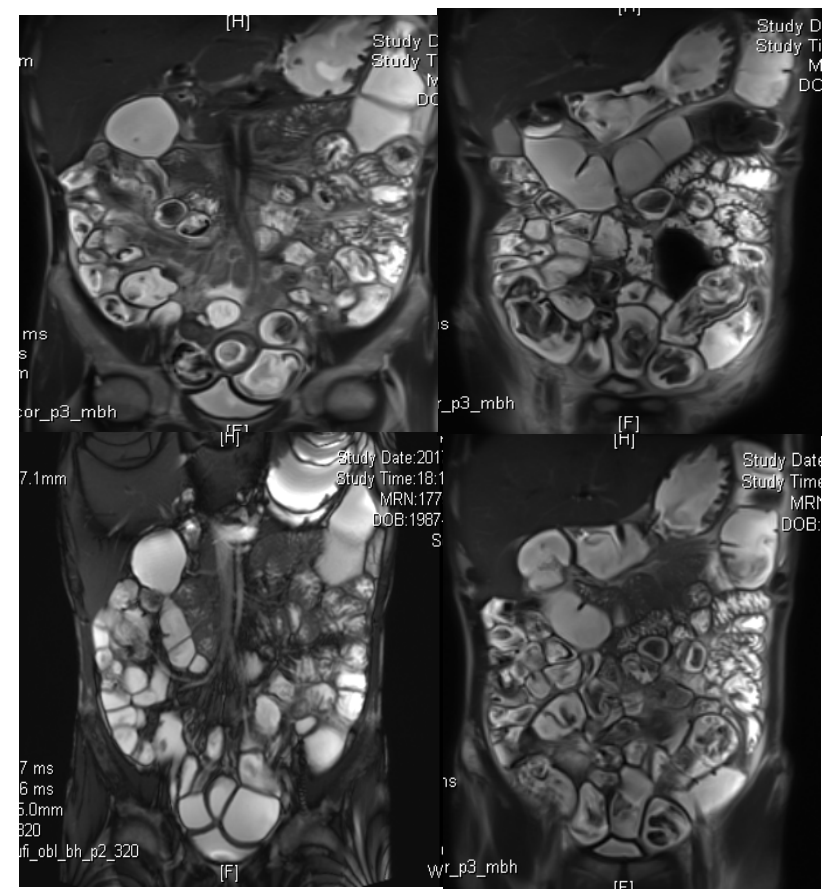

Figure 3. MRE; the ileum many Segmental thickening and abnormal strengthening, Conhon Disease. Between the midriff intestinal canal abnormal signal nodule, considering as swollen lymph nodes

this symptom, accompanied with serious low serum albumin. Usually black stool suggests that some disease in the upper tract, firstly we examined the patient by gastro-endoscopy but found no lesions which could explain the black stool. Then we check him by colon endoscopy. Unfortunately, nothing again. The patient has been examined at another hospital by small intestine endoscopy, which show chronic inflammation and erosion, polyp in the small intestine. MRE is a new technique helping to show the details in small intestine. MRE clearly show the lesions in the patient's small intestine, characterized as CD.

On the other hand, the patient shows serious serum hypo-albumin, probably resulted from the disease activation and the loss from the digestive tract. Positive nutrient support is essential for his recovery.
Furthermore, continuous and regular treatment with immunedepress drug is essential for the control and recovery of CD. In our case report, the patient did not fellow his doctor's treatment to use thalidomide. Immune-depress drug can suppress the activation of this kind of disease, and the digestive tract blooding as well.

\section{Conclusion}

When meeting with unexplained anomia and hyo-alboluimne, we should think about $\mathrm{CD}$, and when gastro-endoscopy and colonendoscopy could not show the obvious changes in the upper and lower intestine, the disease in small intestine should be considered.

Copyright: (C2018 Cheng L. This is an open-access article distributed under the terms of the Creative Commons Attribution License, which permits unrestricted use, distribution, and reproduction in any medium, provided the original author and source are credited. 